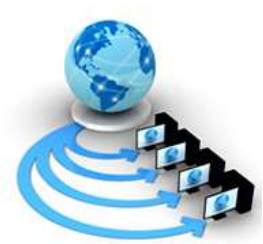

Volume 10, No. 1, January-February 2019

International Journal of Advanced Research in Computer Science

RESEARCH PAPER

Available Online at www.ijarcs.info

\title{
SMS NOTIFICATION IMPLEMENTING INTERNET OF THINGSFOR BARANGAY LABAS, CITY OF SANTA ROSA, LAGUNA
}

\author{
Carlo A. Batitis \\ College of Computer Studies \\ TrimexColleges, Biñan, Laguna, Philippines \\ Michelle V. Arguillon \\ College of Computer Studies \\ TrimexColleges, Biñan, Laguna, Philippines
}

\author{
Elvin S. Alcaide \\ College of Computer Studies \\ TrimexColleges, Biñan, Laguna, Philippines \\ Janedel M. Roldan \\ College of Computer Studies \\ TrimexColleges, Biñan, Laguna, Philippines
}

\author{
Louie F. Agustin \\ College of Computer Studies \\ Trimex Colleges, Biñan, Laguna, Philippines
}

\begin{abstract}
A Barangay is the smallest governmental sector in the Philippines and is the local Filipino name for a village or community. It is governed by elected officials, the topmost being the Punong Barangay or the Barangay Chairperson and assisted by the Sanguniang Barangay or Barangay Councilors.

Due to faster-growing modernization and advance technologies, barangay operations must keep pace with this new kind technology in order to provide a better service. Unfortunately, most of the barangay are still not prepared to incorporate this kind of new technology. One of them is Barangay Labas as one of the 18 barangay of the City of Santa Rosa, Province of Laguna, the barangay is using manual processing of the document and manual processing of delivering information to its residents.

The SMS Notification Implementing Internet of Things for Barangay Labas, City of Santa Rosa, Laguna is system will help the barangay in processing documents request and delivering the fastest information to its residents. This system can process a documents request in fastest and convenient way and delivering information to its residents in fastest way through the help of Short Message Services Technology (SMS).
\end{abstract}

Keywords: Internet of Things (IoT); SMS notification; Web Portal; Information Systems; Documents Management System

\section{INTRODUCTION}

Barangay Labas is one of 18 barangays in City of Santa Rosa, Province of Laguna. It is located on a southeast portion of Santa Rosa City town proper. It is considered as one of the most developed and progressive barangay in the City of Santa Rosa.

In terms of public services, barangay officials and its staff are doing their best to accommodate all the transactions and inquiries of its residence. But despite their hard work, there are still some factors that need to improve. Since they are using the manual process of giving information to its residents and manual processing of barangay documents request and other transactions. Barangay official and its staff encounter problems and difficulties in spreading news and information to its residents and slow processing of barangay documents request due to difficulties in verifying and retrieving a record of the requestors. Currently, the barangay officials and its staff are using manual processing of different barangay services like requesting barangay documents and spreading news and information.

In requesting barangay documents, the problems encountered by barangay staff are the long process of verifying the requestors information due to barangay staff only use printed or hardcopy of barangay master list in finding requestor's name. This may cause problem and timeconsuming process on the part of barangay staff, and it may cause a delay on the requestors. Another problem encountered is the error in inputting data on barangay documents due to barangay workers manually input or write the requestors information on documents. Also in disseminating barangay news and information, the barangay also encountered some difficulties. They only use tarpaulins to spread the information and post on different parts of the barangay. This is why the proponents will develop a project that will help and benefit the Barangay especially its residents, barangay official, and its barangay staff.

The SMS Notification Implementing Internet of Things for Barangay Labas, City of Sanata Rosa, Laguna is a system that will help the barangay to improve their operations in giving the fastest way of spreading news, notifications, informations and announcements of barangay and processing of different barangay documents that will give convenience to the residents requestors and to speed up and facilitate barangay workers jobs. 


\section{DESIGN OF THE STUDY}

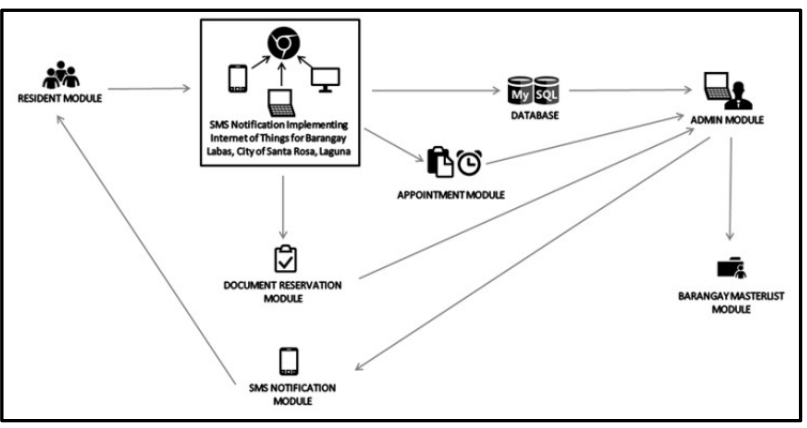

Figure 1: System Architecture

Figure 1 shows the different component of the Web Application System. Currently, barangay has no established system in processing request and giving notification to its residents. On the proposed project, the user will be responsible for browsing the website, requesting documents, make an appointment to barangay and receive SMS notifications from barangay. Admin will be responsible for updating websites, accepting and declining request, notify residents, and updating barangay master list.

\section{Network Design Infrastructure}

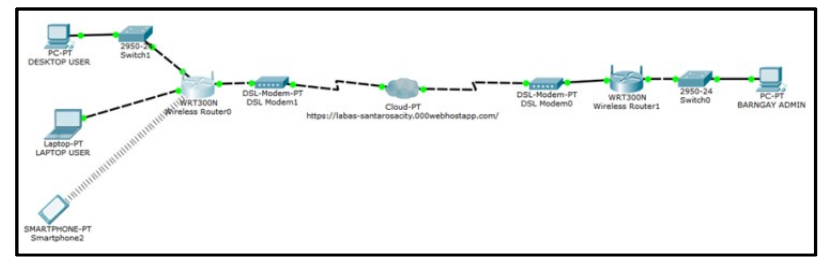

Figure 2: Network Design Infrastructure

Figure 7 shows the network design infrastructure of Web Application System. To view the Web Application System, the user must use a desktop computer, Laptop or a smart phone using an internet connection. Barangay Admin will be responsible on all the updates and cater all the inquiries on the system through an admin computer with an internet connection.

\section{LITERATURE SURVEY}

\section{IoT - Internet of Things}

As technology is evolving, we see automation in a different field. A fully independent office will see in the future. People frequently request to have automated control over numerous electrical appliances in office like light, fan, microwave oven, and computer. This project gives a solution which helps in completing the task effectively. A universal switch has been recognized using Arduino Uno Atmel Microcontroller, Android application and GSM modem along with fire and human sensors the whole of which constitutes Office Automation System. Sahana H S ${ }^{1}$, Sandeep V S ${ }^{1}, \mathrm{R}^{1}$ Shwetha, J' ${ }^{1}$ Sowmya, KS Krupa, Office Automation System Using Internet of Things, (July 2017)

While the Internet of Things (IoT) give important advantages over outdated communication technologies for smart grid and smart home applications, these applications are still very unusual. Depend on a broad literature review; this paper aims to contribute towards narrowing the gap between the existing state-of-the-art smart home applications and the prospect of their integration into an IoT enabled environment. We propose a holistic framework which incorporates different components from IoT architectures/frameworks proposed in the literature, in order to efficiently integrate smart home objects in a cloud-centric IoT based solution. We identify a smart home management model for the proposed framework and the main tasks that should be performed at each level. We additionally discuss practical design challenges with emphasis on data processing, as well as smart home communication protocols and their interoperability. We believe that the holistic framework ascertained in this paper can be used as a solid base for the future developers of the Internet of Things based smart home solutions. Biljana L RisteskaStojkoska, Kire V Trivodaliev, Journal of Cleaner Production 140, 1454-1464, 2017

\section{Short Message Services (SMS)}

Texting or SMS (short message service) is a process of communication that sends text among smart phones - or from a PC or handheld to a smart phones. The "short" part comes from the maximum size of the text messages: 160 characters (letters, numbers or symbols in the Latin alphabet). Christine Erickson (Sept. 21, 2012).

On December 3, 1992, the first text message was sent by a software engineer named Neil Papworth to a Vodafone director Richard Jarvis. It was received on his husky Orbitel 901 cell phone. It contains, "Merry Christmas"."Heather Kelly, CNN (December 3, 2012) OMG, the text message turns 20. But has SMS peaked?

For Filipinos, texting has become one of the easiest and cheapest modes of communication across long distances - so much so that the Philippines has been popularly referred to as the world's texting capital. Alfred Bayle / Inquirer.net (December 04, 2017)

Unlike messaging apps such as Facebook Messenger and Viber, texting does not require a Wi-Fi connection to send a very basic text message. In countries like the Philippines where connectivity is a widespread problem, one can expect texting to still be a necessary means of communication. Alfred Bayle/JB Inquirer.net (December 04, 2017)

\section{Online Appointment System}

The software of Excellence (SoE) has produced an online appointment booking system that integrates with a dental practice's recall management.

This new approach has been developed as a direct response to feedback from dental professionals and features software that identifies patients due for recall on a daily basis according to defined criteria, preset by the practice. The software automatically sends recall messages via email or text with a link prompting the patient to access a practicebranded online booking facility, detailing available appointment times with the patient's own clinician. The patient selects the desired appointment, and the software automatically identifies the patient and reserves the appointment, updating the practice's computerized 
appointment book in real time. Patients receive a confirmation email which can also be customized by the practice to include a map, an image of the practice and dentist, opening hours, new treatments and can even be used to promote special offers. Experienced practices can also configure the software to 'smartly' select appointment times that they may traditionally find difficult to fill.

SoE's new online recall booking module provides a software solution that provides more than simply a mechanism for a patient who needs an appointment. This new technology is an integral part of the recall process that works via email and on smartphones, stimulating successful recall response rates and making a measurable and significant impact on the overall efficiency of a practice. BDJ volume 212, page 198 (25 February 2012)

\section{Barangay System}

In the study of students of Colegio de San Antonio de Padua of DanaoCity(2017) is that the main goal of the study to develop computerized Barangay Information System that can automate the record-keeping process in order to create well-organized and exact reports and accurate automated files management. Furthermore, the system will be able to protect residents confidential records, to easily update residents profile, provides a backup database of all records and to issue certificates/permits and other related records. It was piloted at Barangay Poblacion, Danao, Cebu City. Moreover, the system will be beneficial to residents of the barangay and barangay employees who handle the system as well as the barangay itself. This also ensures that all the records are intact and updated, as well as census-based to monitor the population of the locale and safe for accessing by an unauthorized user.

\section{RESULTS AND DISCUSSION}

A Web Application System is a Website that offers different services like giving notifications, information, inquiries and online business transactions. Users can easily access through the internet using a standard browser — the Barangay Labas Web Application System that helps the barangay to speed up the process and facilitate the task of barangay workers. This website will also provide more extensive services to its residents.

The main purpose of the study create a barangay web application system that will benefit the barangay on its operations and immediately respond to all the request and inquiries of its residents.

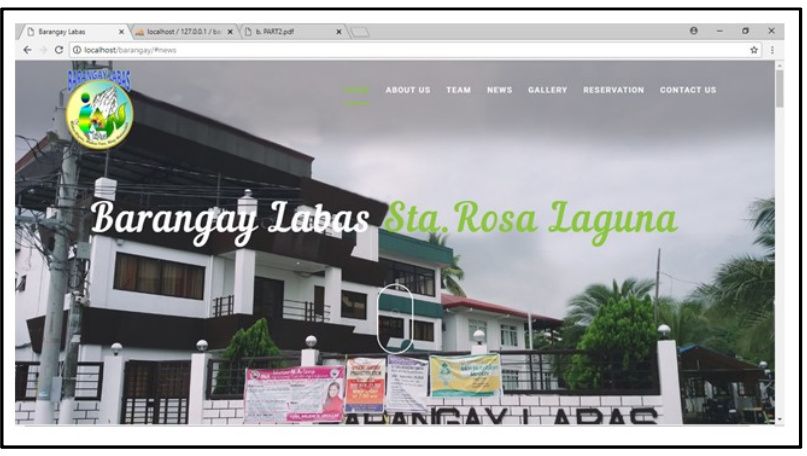

\section{Figure 3: The Barangay Labas Web Application System}

Figure 3 shows the Barangay Labas Web Application System. It contains barangay history, information, activities, projects, latest news and online services that will help its residents.

The first aim of the study is to develop a website that can view all the activities, projects, news, and informations of the barangay.

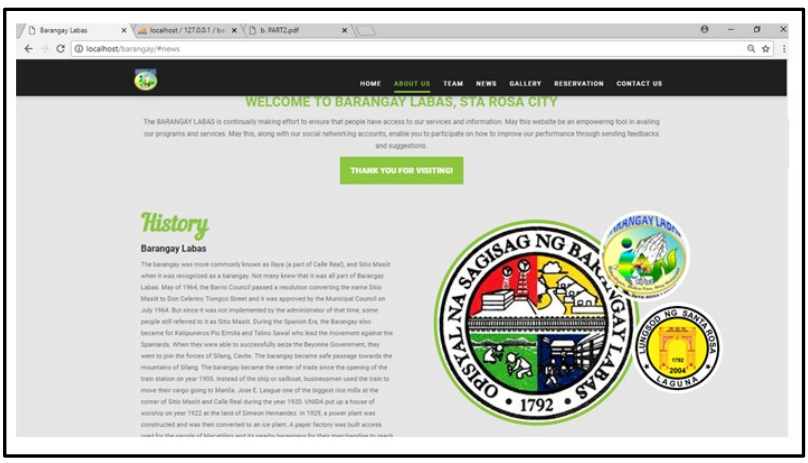

Figure 4: The Barangay History

Figure 4 shows the Barangay Labas History. It published the rich history of the Barangay and Figure $17 \mathrm{~b}$ shows the List of Barangay Officials.

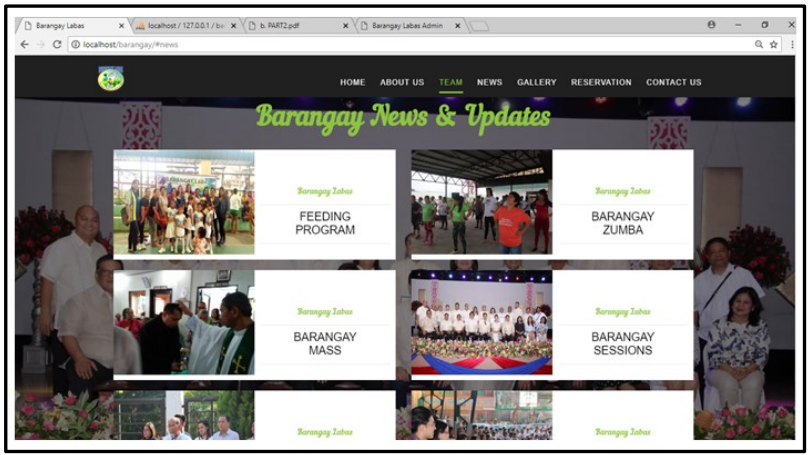

Figure 5: Barangay Updates

Figure 5 shows the different news and updates of barangay

The second aim of the study is to create a system that will give convenience to all the residents especially to all employees, businessman and student in requesting barangay documents.

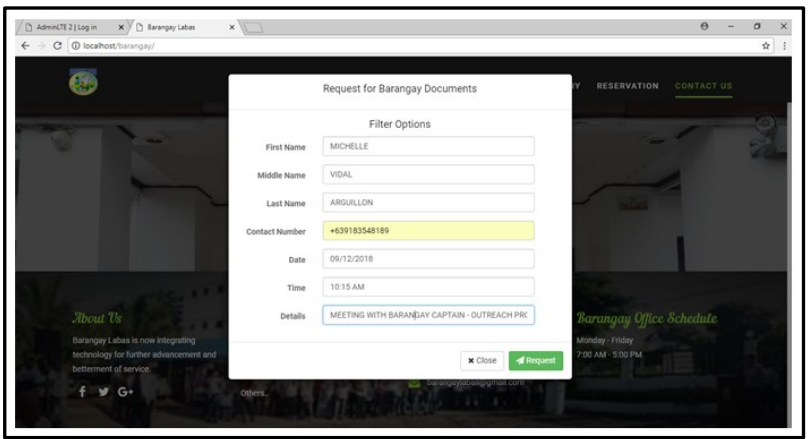

Figure 6: Request for Barangay Documents 
Figure 6 shows the request for barangay document forms where the user can make request documents.

The third and last aim of the study is to create a system that will notify immediately all the residents via SMS- Short Message Services.

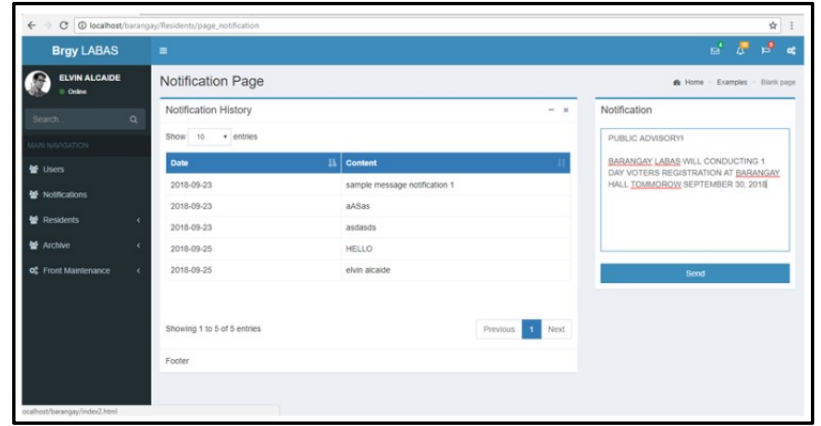

Figure 7: The Barangay Labas SMS Notification

Figure 7 shows the Notification Page where admin can create a Notification like new, advisories, warnings, etc.

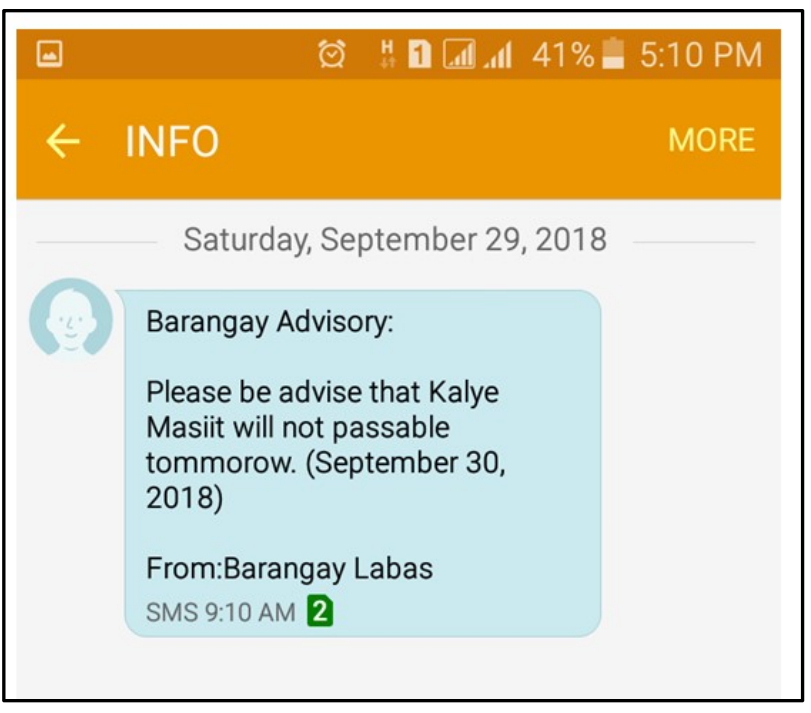

Figure 8: SMS Notification

Figure 8 shows the sample SMS notification receive by residents from the System.

\section{CONCLUSIONS}

Based on the objectives of the study and the results of the evaluations conducted, the following conclusions were drawn:

1. Residents can view all the activities, projects, latest news and information on barangay through a web application system that can browse on the internet. This will help all the residents to be kept updated even though they are secluded or away from barangay.

2. Resident can make an online documents request and an online appointment to barangay. This online services will help all the requestor especially to all the entrepreneurs, employees, and student that lack of time to request and visit the barangay.
3. With the help of Web Application System and Short Message Services Technology, residents immediately notify about Warning and Calamity status, Tips and Advisories, and Barangay Important Announcements.

\section{Recommendations:}

The researcher of the study further recommends the following:

1. Add all barangay documents.

2. Adding an Android application to take full advantage in requesting documents and appointments.

3. Adding Payments in all documents that have a processing fee.

4. Add GPS in tracking the resident's address.

5. Add online blotting module, tricycle franchising module, women's desk module and other activities of barangay that uses a manual process.

\section{REFERENCES}

[1] Bayle, Alfred (December 04, 2017). World's First Text Message Turns 25 years old. Retrieve from http://technology.inquirer.net/70008/worlds-first-textmessage-turns-25-years-old.

[2] BDJ (February 25, 2012). Smart Online Appointment Booking. Retrieved from https://www.nature.com/articles/sj.bdj.2012.166.

[3] Erickson, Christien (September 21, 2012). Text Messaging History. Retrieved from http://mashable.com/2012/09/21/text-messaginghistory.

[4] Farahat, Ahmed (May 21, 2015). The Information System: The Manual Process Model. Retrieve from http://www.engineering-bachelorsdegree.com/business-informationmanagement/uncategorized/the-information-systemthemanual-process-model/.

[5] Greenguard, Samuel (Sept. 24, 2014). A Brief History of Internet of Things. Retrieved from. http://www.baselinemag.com/networking/slideshows/abrief-history-of-the-internet-ofthings.html\#sthash.n766SXR4.dpuf.

[6] Kelly, Heather (December 03, 2012). OMG, The Text Message Turns 20. But Has SMS Peaked? Retrieved from

https://edition.cnn.com/2012/12/03/tech/mobile/smstext-message-20/index.html.

[7] Lopez, (November 2013). Lopez Research. An Introduction to the Internet of Things. Retrieved from. Retrieved from. http://www.cisco.com/c/dam/en_us/ solutions/ trends/iot/introduction_to_IoT_november.pdf.

[8] Roos, Dave (June $-0 \overline{5}$, 2007). How Electronic Notification Work. Retrieve from https://computer.howstuffworks.com/e-mailmessaging/how-electronic-notifications-work.htm.

[9] RisteskaStojkoska, Kire V Trivodaliev (2017) Journal of Cleaner Production 140, 1454-1464. Retrieve from https://scholar.google.com/citations?user=Tg2BCMAAAAJ\&hl=en.

[10] Saigh, Michael, Arnd, Kevin (July 20, 2012). Personal Safety Mobile Notification System. Retrieve from https://patents.justia.com/assignee/saigh-and-son-llc.

[11] System. Sahana H S ${ }^{1}$, Sandeep V S ${ }^{1}, R^{1}$ Shwetha, ${ }^{1}$ Sowmya, KS Krupa (July 2017). Office Automation System Using Internet of Things. Retrieved from http://www.irjet.in/volume-4-issue-07-july-2017. 
[12] Senados, Greggy (March 30, 2017). Cebu City Launches Smart Infocast. Retrieve from https://www.cebucity.gov.ph/home-44293/40news/4096-cebu-city-launches-smart-infocast.

[13] Schneider, Stan (Oct. 9, 2013). Understanding the Protocols behind the Internet of Things. Retrieve from http://electronicdesign.com/iot/understandingprotocols-behind-internet-things,

[14]Zimmers, Steven, Davis, Daniel (March 12, 2012). Alert Notification System. Retrieve from https://patents.justia.com/inventor/steven-l-zimmers. 